\title{
Predicting referral practices of traditional healers of their patients with a mental illness: an application of the Theory of Planned Behaviour
}

\author{
K Sorsdahl, DJ Stein, AJ Flisher \\ Department of Psychiatry and Mental Health, University of Cape Town, Cape Town, South Africa
}

\begin{abstract}
Objective: Although many studies indicate that traditional healers are willing to collaborate with Western practitioners in South Africa, none focus specifically on mental health care, and none use a theory of health behaviour to explain their findings. The present study applies the Theory of Planned Behaviour (TPB) to predict traditional healer referral practices of patients with a mental illness. Method: One hundred traditional healers were first interviewed to assess the TPB variables and were contacted again 5 months later to measure self-reported behaviour. Results: Herbalists were less likely than other types of healers to refer patients with a mental illness to Western health professionals. From the TPB application, the following cognitive variables were found to predict intentions: attitudes $(B=0.612, p<0.01)$; perceived behavioural control $(\beta=0.355, p<0.01)$; and past behaviour $(\beta=0.704, p<0.01)$. Subjective norms and knowledge of mental illness did not predict intentions. Finally, past behaviour $(\beta=0.297$, $p=0.040$ ) and intentions to refer patients $(B=0.758, p<0.01)$ predicted greater self-reported behaviour. Conclusion: The TPB may be a useful theoretical model for predicting the referral practices of traditional healers. The empirical data here may be useful for future work designing interventions to provide traditional healers with the information and skills they require to appropriately refer patients with mental illness.
\end{abstract}

Keywords: Medicine, African traditional; Referral and Consultation; Decision Analyses; South Africa

Received: 27-06-2011

Accepted: 21-11-201 1

doi: http://dx.doi.org/10.4314/ajpsy.v16il.6

\section{Introduction}

Traditional healers are respected members of the community who play a vital role in the lives of many South Africans. There are a range of different types of alternative practitioners in South Africa. For example, traditional healers include the herbalist and the diviner. ${ }^{1,2}$ The diviners are believed to be specialists in divination within the supernatural context which gives them the ability to divine the cause of illness and misfortune. The herbalist specializes in the production of herbal medicines. ${ }^{3}$ Religious and spiritual leaders include faith healers who integrate Christian ritual and traditional practices, and belong to one of the Independent African churches. ${ }^{4}$

\section{Correspondence}

Dr. K Sorsdahl

Department of Psychiatry and Mental Health, J2, Groote Schuur Hospital,

Observatory, Cape Town, 7925, South Africa

email: Katherine.sorsdah|@uct.ac.za
Results of small studies conducted in South Africa with patients attending health facilities reveal that approximately one-half (41-61\%) of patients with a mental disorder have consulted a traditional healer.5, 6 However, more recently Sorsdahl and colleagues examined the role of traditional healers in mental health seeking behaviour within a nationally representative sample of adults. Results revealed that a minority of participants with a lifetime DSM-IV diagnosis obtained treatment from Western (29\%) or alternative (20\%) practitioners. Traditional healers were consulted by $9 \%$ of the respondents and 1 1\% consulted a religious or spiritual advisor. $^{\text {? }}$

However, despite their use by South Africans for their mental health care concerns, there is a great deal of debate over their legitimacy and views toward collaboration. To some extent the different views put forward in the literature can be divided into three, however, this is a heuristic classification and not intended to encompass the views of all authors. First, there is a "classical" view. The classical view holds that there is disjuncture between 
scientific Western medicine, and the magical thinking of traditional healing. ${ }^{8}$ One group advocating this view is Doctors for Life (DFL), an international organization that represents a large number of medical doctors, dentists, veterinarians and other professionals, which views traditional medicine as ineffective and unsafe. Second, there is a "critical" view. The "critical" view criticizes the conceptual basis of science and medicine, arguing that these merely reflect one particular way of looking at the world, which is not necessarily privileged (the relativist or 'emic' perspective in cross-cultural research). ${ }^{8}$ Some in this view, such as the World Health Organization (WHO) and the United Nations Children's Fund (UNICEF) argue that both Western medications and traditional agents can have therapeutic efficacy.

A third perspective might be termed "integrative". In this view, while both Western medicine and traditional healing are social activities (and therefore reflect particular cultural values), illnesses and interventions require an understanding of underlying psychobiological mechanisms (and this explains why both medical and traditional interventions can be effective and safe, or ineffective and potentially toxic). ${ }^{8}$ To understand why particular interventions are widely accepted and used, one certainly needs an understanding of the relevant socio-political context. However, to determine whether particular interventions are effective or safe, one needs to collect data rigorously (e.g. randomized placebo-controlled trials), and one needs to understand the underlying mechanisms by which they work.

Despite these varying views, South Africa has moved towards officially recognizing traditional healers as healthcare providers in the country. This Traditional Health Practitioners Act recognizes the estimated 200000 traditional healers in South Africa as health care providers. ${ }^{9}$ Additionally, the South African government has recently published a draft national policy on African Traditional Medicine (ATM). The policy advocates for Western and traditional medicine to function side by side within the primary health care system and not the integration of the two systems. ${ }^{10}$

If Western and traditional medicine are to work side by side, collaboration in the form of referral is essential. Although numerous studies have qualitatively examined referral practices of health care professionals for mentally ill patients, they focus more on the referral practices of primary health care workers ${ }^{11,12}$; few have focussed on traditional healers. Studies that did report on the referral practices of traditional healers investigated several medical conditions such as hearing impairment ${ }^{13}$, HIV and AIDS ${ }^{14,15}$, tuberculosis ${ }^{16}$, and malaria. ${ }^{17}$ The results of these studies suggest that traditional healers are willing to collaborate with Western practitioners and report referring patients if they are not responding to treatment. However, none of these studies focuses specifically on mental health. Furthermore, willingness to collaborate does not necessarily equate to referral of patients. For example, an intervention focussed on HIV/AIDS and tuberculosis and collaboration reported that $99 \%$ of the participants reported a "willingness" to collaborate, but only $43 \%$ were actually referring. ${ }^{15}$ Identifying factors associated with traditional healer referral practices of their mentally ill patients is central for developing and designing interventions to ensure traditional healers refer more frequently and appropriately. If the patients of traditional healers require urgent standard treatments, or are not responding to treatment, the healers should be encouraged to refer them to a Western healthcare professional. Behavioural theories can assist with identifying the determinants of behaviour, which is imperative when developing interventions since those which address such determinants are more likely to be effective. ${ }^{18}$

Given the apparent significance of attitudinal factors when addressing the concept of referral, the Theory of Planned Behaviour (TPB) may be a useful theoretical framework to address this issue. This theoretical model predicts cognitive variables that influence intention to perform a particular behaviour; it recognises attitudes, perceived subjective norms and perceived behavioural controls as influences on behaviour. 'Attitude' is an individual's positive or negative belief about performing a specific behaviour, while 'subjective norms' are determined by whether or not he/ she perceives that important others in their life think they should engage in that particular behaviour. Perceived behavioural control refers to a persons' perception of the ease or difficulty of performing the behaviour of interest. The more favourable the attitude and subjective norm with respect to the behaviour and the greater the perceived behavioural control, the stronger the individual's intention will be to perform the behaviour under consideration. Each of these three direct determinants of behavioural intention is influenced, in turn, by an indirect determinant. Indirect determinants are based on a set of salient beliefs and evaluations of these beliefs.

The TPB has been shown to be appropriate to predict a number of health behaviours including, condom use, use of various substances, engaging in physical activity, and engaging in sports. ${ }^{19}$ Furthermore, the TPB has been shown to be applicable in African populations. ${ }^{20,21}$ To date, no studies have applied the TPB to predicting traditional healer practices. Therefore, the present study sought to apply an extended version of the TPB, containing separate measures of knowledge and past behaviour to the prediction of traditional healer referral practices, specifically for patients with a mental illness.

\section{Method \\ Participants}

A convenience sample of traditional healers who practice in the Queenstown area of the Eastern Cape Province were approached to participate in the study. The study utilized a "snowball" or acquaintance sampling strategy.

\section{Procedure}

This study was conducted in four phases:

Phase 1- instrument development: The aim of this exploratory qualitative phase was to gain an understanding of how traditional healers reach a decision to refer adolescents and adult patients suffering from a mental illness to Western health professionals. The findings of this phase resulted in the construction of questionnaire items relating to behavioural beliefs, normative beliefs, and control beliefs about referral practices and are described elsewhere. ${ }^{22}$

Phase 2- the pilot: A pilot study conducted with 25 traditional healers was used to determine the test-retest reliability of the indirect measures. The interval between the pre and post-test was 8 weeks. 
Phase 3- administering complete survey: Of the 143 traditional healers who were approached to participate in this final study, only 100 full one-on-one interviews were conducted. Thirty-nine traditional healers did not work with mentally ill patients while four interviews were stopped due to the healers being intoxicated. The study utilized a "snowball" or acquaintance sampling strategy. Interviews were conducted in a variety of locations, ranging from the traditional healers home, the car and traditional healer surgeries.

Phase 4- eliciting self-reported behaviour construct: All traditional healers were contacted again 5 months later either by cell phone (79\%) or in person (21\%) to elicit information on their referral practices. This process took 2 weeks as locating traditional healers was a timely process.

\section{Ethics}

The study was approved by the Research Ethics Committee of the Health Sciences Faculty of the University of Cape Town.

\section{Measures}

During the exploratory qualitative phase, it became apparent that it was regular practice for traditional healers to refer those who are extremely violent and weak (require a drip) to a Western doctor. Therefore, the instrumentation in this study refers to attitudes, subjective norms and beliefs of traditional healers for patients who are not violent or weak.

Attitude: The direct measure of attitude was assessed by taking the mean four responses to the statement, "Referring my mentally ill patient to a Western doctor would be....". This statement was evaluated on 4-point unipolar (+1 to +4) scales with the endpoints: useful/not useful; very wrong/not wrong at all; foolish/not foolish at all; very good/not good at all. The Cronbach's alpha for the scale was .83.

Subjective Norm: Perceived social pressure to refer mentally ill patients to a Western doctor if they are not responding to traditional treatment was assessed with a 3 item measure using a 4 point unipolar (+l to +4 ) scale (eg. "People who mean a lot to me would like me to refer my mentally ill patients to the Western doctor?" (YES-NO) The mean of the items made a scale with good internal reliability (Cronbach's alpha $=.90)$.

Perceived Behavioural Control (PBC): Items assessing PBC included questions eliciting traditional healers' self-efficacy and their beliefs about the controllability of referring their mentally ill patients to a Western doctor if they are not responding to treatment. Confidence in one's own ability was assessed using the responses to two items (eg. "I am confident that I could refer my mentally ill patients to a Western doctor if I wanted to (YESNO). All items were measured using 4 point $(+1$ to +4$)$ unipolar scales. Cronbach's alpha indicated moderate reliability for the scale (.65).

Behavioural Beliefs: The behavioural belief scale included 7 items on outcome expectancies and 7 corresponding items to measure evaluation of the outcomes. Each outcome expectancy score was multiplied by its corresponding outcome evaluation item, and the products were summed for a weighted behavioural belief score, with higher scores indicating more positive behavioural beliefs.
Normative beliefs: The normative belief scale included 3 items on normative belief referents and 3 for the corresponding motivation to comply with the referents. Each normative referent score was multiplied by its corresponding motivation to comply score, and the products were summed for a weighted normative beliefs score, with higher scores indicating stronger social influence or normative beliefs for referring mentally ill patients.

Control beliefs: The control belief scale included 4 items on control belief factors that may facilitate or impede carrying out the behaviour and 4 corresponding items for control belief power. Each control factor score was multiplied by its corresponding power of the factor, and the products were summed for a weighted control belief score.

Behavioural Intention: Behavioural intention was measured using a single item question: "How many patients do you expect to refer in the next month that is not violent or weak" (all of them-none of them)".

Past Behaviour: A single item measured traditional healers' past behaviour. The item read "Have you ever referred a mentally ill patient to a Western doctor that was not violent or weak (requiring injection or a drip)?"

Knowledge: A knowledge measure comprising of 13 items was developed for the study assessing Western symptoms of mental illness. A scale was computed by taking the sum of all the knowledge indexed items.

\section{Analysis of Data}

All data analyses were conducted using SPSS 16.0 with the exception of PATH analyses which were conducted using MPLUS. Test-retest reliability was conducted to assess the consistency of the indirect measures across time. This type of reliability assumes that there will be no change in the quality or construct being measured. Path analysis, also known as causal modeling, focuses on examining the web of relationships among measured variables. Although we would have liked to include measurement models in this analysis, in keeping with the methods described by Ajzen ${ }^{19}$, because of the relatively small sample size, a path analysis was conducted.

\section{Results}

Results are presented in accordance with the aims of this study. Results are divided into: (a) characteristics of traditional healers; (b) applicability of basic constructs of TPB in the referral practices of traditional healers and predictability of the modified version of the TPB, including knowledge and past behaviour.

\section{Characteristics of traditional healers}

Table I summarizes the characteristics of the traditional healers interviewed for this study. The majority of the traditional healers interviewed were women (65\%), with an average age of 49 (range 22-79) years. The average length of training taken to become a traditional healer (under supervision of experience healer) was 3 years. A majority of the healers (75\%) in this study can be classified as igqirha or diviners (75\%) (who have diagnostic powers), while a minority 
can be classified as ixhwele or herbalists (14\%)who dispense herbal medicines and faith healers (5\%). Although there were no significant associations between demographic variables and TPB constructs, the type of traditional healer differed significantly on intention to refer. Ixhwele (herbalists) were less likely than the other types of traditional healers to refer their patients to a Western health care professional $\left(\chi^{2}=3.96\right.$, $\mathrm{df}=1 \mathrm{p}=0.047$ ).

\begin{tabular}{|l|l|l|}
\hline $\begin{array}{l}\text { Table I: Socio-demographic and practice characteristics of } \\
\text { traditional healers (N=100) }\end{array}$ & $N$ & $\%$ \\
\hline Characteristic & 65 & 65 \\
\hline $\begin{array}{l}\text { Gender (\%) } \\
\text { Female }\end{array}$ & 75 & 75 \\
\hline $\left.\begin{array}{l}\text { Type of Healer (\%) } \\
\text { Igqirha(diviner) } \\
\text { Ixhwele(herbalist) } \\
\text { Abathandazeli (faith healer) } \\
\text { Igqirha \& Ixhwele } \\
\text { Igqirha, Ixhwele \& Abathandazeli }\end{array}\right) \begin{array}{l}14 \\
5\end{array}$ \\
\hline Age in years (mean, sd) & 3 & 3 \\
\hline Years of education (mean, sd) & $49(13)$ & 3 \\
\hline Duration of training in years(mean, sd) & $3(3.72)$ & \\
\hline Duration of practice in years (mean, sd) & $14(10)$ & \\
\hline Number of patients per week (mean, sd) & $8(9.54)$ & \\
\hline
\end{tabular}

\section{Applicability of the TPB in the referral practices of traditional healers}

Basic TPB Model in Predicting Traditional Healer Referral Practices

Reliability analyses were conducted for each component of the TPB model. Cronbach's alpha was $\alpha=0.83$ for the attitudes items, $\alpha=0.90$ for the subjective norms items, $\alpha=0.60$ for the perceived behavioural control items. Table II summarizes the descriptive statistics for all TPB constructs.

Indirect and direct measure of attitudes and perceived behaviour control toward referring mentally ill patients were moderately correlated (attitude $r=.0 .77, \mathrm{p}<.001 ; \mathrm{PBC} 0.70 \mathrm{p}$ $<.001$; SN 0.50 p $<.001)$.
Path analysis using MPLUS was used to examine the basic TPB model with respect to the referral practices of traditional healers. The chi-square test of model fit was not significant $\left(\chi^{2}\right.$ $=1.25, \mathrm{p}=.54)$ and the RMSEA value was well below the value of .06 $(p<0.01)$ recommended by Hu and Bentler ${ }^{23}$ as an upper boundary, so we can conclude that the proposed model fits the data well. Looking at the individual TPB constructs, more favourable attitudes $(B=0.55, \mathrm{p}<0.01)$; and more perceived behavioural control $(\beta=0.366, p<0.01)$, predicted greater intentions to refer patients to a Western healthcare professional. Contrary to expectations, stronger subjective norms did not predict intentions ( $\beta=0.01$, ns). Additionally, stronger intentions to refer patients predicted greater selfreported behaviour $(\beta=0.76, p<0.01)$.

\section{Modified Version of the TPB}

Path analysis was used to examine the basic TPB constructs in addition to two other constructs: Past Behaviour and Knowledge. The chi-square test of model fit is not significant $\left(\chi^{2}=3.44, p=.84\right)$ and the RMSEA value is $\mathrm{p}<0.01$. We can conclude that the proposed model fits the data well. Similar to the results in the basic model, attitude $(B=0.61, p<0.01)$, and perceived behavioural control $(\beta=0.36, p<0.01)$, significantly predicted intention to refer, while subjective norms did not ( $\beta=-0.10$, ns). Although past behaviour $(\beta=$ 0.70, $\mathrm{p}<0.01$ ) and self-reported behaviour $B=0.30, \mathrm{p}=0.04$ ) were strong predictors of intentions to refer, knowledge was not $(B=0.25, n s)$. Additionally, stronger intentions to refer patients predicted greater self-reported behaviour $(B=0.75$, $\mathrm{p}<0.01$ ) (Figure 1).

\section{Figure 1: Standardized coefficients estimated in a path} model predicting traditional healer referral practices

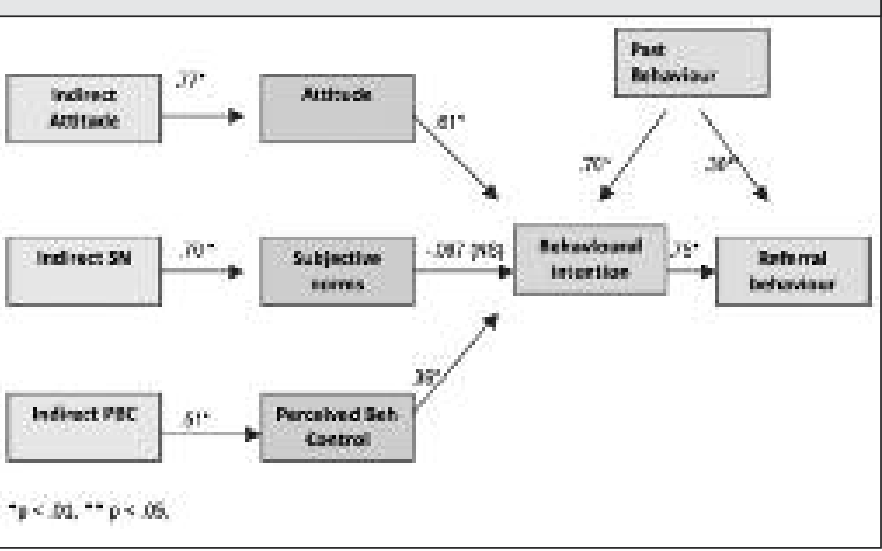

\section{Table II : Means, standard deviations and Cronbach alphas}

\begin{tabular}{|l|l|l|l|l|l|}
\hline Measure & No. of ltems & Range & Mean & S.D. & Alpha \\
Direct Attitude & 4 & $1-4$ & 2.54 & 1.00 & .83 \\
Direct SN & 3 & $1-4$ & 2.47 & 1.06 & .90 \\
Direct PBC & 5 & $1-4$ & 0.86 & 0.96 & .60 \\
Behavioural Beliefs & 7 & $-31-34$ & 4.14 & 14.0 & - \\
Normative Beliefs & 3 & $-16-24$ & 0.50 & 1.68 & - \\
Control Beliefs & 11 & $-28-28$ & 1.79 & 0.97 & - \\
Behavioural Intention & 4 & $1-4$ & 1.4 & 0.49 & - \\
Past Behaviour & 1 & $1-2$ & 2.14 & 1.06 & .74 \\
Knowledge & 13 & $1-5$ & & \\
\hline
\end{tabular}




\section{Discussion}

The main results of this study are as follows:

- Herbalists were less likely than any other type of healer to refer mentally ill patients to Western health professionals.

- A number of constructs were found to be predictors of traditional healer referral practices. These included attitude, perceived behavioural and past behaviour, and intention to refer.

- Subjective norms and knowledge of mental illness were not predictors of traditional healer referral practices.

The initial finding that diviners are more likely than herbalists to refer mentally ill patients to Western healthcare professionals can be explained by a number of factors. There are many differences between the training and treatment practices of diviners and herbalists. Diviners are predominantly female and are 'called by their ancestors' to the profession. ${ }^{24-27}$ Although most diviners are trained in prescribing herbal treatment, others refer them to the "specialists", the herbalists. ${ }^{28}$ Herbalists are predominantly male and are comparable to pharmacists in Western medicine. Most of the herbalists reported great faith in the effectiveness of their treatments and therefore any referral would not be appropriate for the patient and voiced serious concern over Western medicine and their motivation for collaboration.

Attitude, perceived behavioural control, and past behaviour, were found to significantly predict traditional healer referral practices. Not surprisingly, traditional healers who reported more favourable attitudes towards Western medicine and believed that their practices are useful in some way (even if it is just to provide a drip to dehydrated patients), were more likely to refer their patients. Additionally, traditional healers who believed that they had control over referring, were confident that they could perform the behaviour and perceived that the behaviour would be less difficult to perform, had greater intentions to refer. It is important to mention here that in some areas due to inadequate resources, there is often very limited access to Western medicine, further complicating this problem of perceived control. It is not surprising that past behaviour proved to be a strong predictor of traditional healer referral practices, since its inclusion is often supported in the available literature.29,30 Those healers that had previously referred a mentally ill patient to a Western doctor were more likely to refer again.

Although some of the constructs in the TPB predicted traditional healer referral practices, subjective norms were not found to be a significant predictor. Unlike Western health professionals, traditional healers work rather autonomously. Ajzen and Fishbein have noted that due to variations in the behaviour and populations under investigation, it should not be expected that all TPB factors (attitudes, subjective norms and perceived behavioural control) will always be significant. ${ }^{31}$ Indeed, several studies have found stronger support for some components of the TPB than others with subjective norms often emerging as the weakest predictor. ${ }^{32,33}$

Additionally, knowledge was not a predictor of traditional healer referral practices. The available research indicates that traditional healers identify a mentally ill patient through extremely abnormal behaviour and episodes of violence. ${ }^{34,35}$ Even though traditional healers do have a coherent concept of mental illness, it is often equated solely with severe behavioural disturbances. ${ }^{36}$ Therefore, it may be that the questions used to assess traditional healer knowledge were not appropriate for this population, since their explanatory models of mental illness differ more from Western explanatory models.

The results of the present study have a number of implications. To begin with, the traditional healers in this study appear to have a relatively low level of mental health literacy. Disorders such as depression are generally not identified as a mental illness by traditional healers. Secondly, it is not clear that traditional healers have appropriate guidelines on how long they should treat their patients with a mental illness before referring. While not specifically aimed at mental health, studies have shown that treatment delay in receiving essential biomedical treatment resulting from consultation with a traditional healer can have dire consequences for the patient. ${ }^{16,17}$ Finally, although encouraging traditional healers to refer their mentally ill patients to the local clinics is a step in the right direction, it should be noted that there is a significant problem of non-detection in primary care settings. Many patients with a mental illness are either undiagnosed or misdiagnosed and, therefore, inadequately treated in such settings. ${ }^{37}$

Several limitations of this study must be considered when interpreting these findings. First, questions could be raised about whether participating in the study caused healers to change their referral behaviour and, thus influence the results (i.e. a Hawthorne effect). Secondly, self-reports rather than objective measures of behaviour were obtained due to budget and time restraints. Thirdly, since a convenience sample of traditional healers from the Eastern Cape was utilized through a snowballing method, which seems to have drawn more diviners than herbalists, the results cannot necessarily be generalized to the South African traditional healer population. Finally, the study was conducted in an African language, which the person collecting the data (KS) does not speak.

\section{Conclusion}

Despite limitations the results of this study emphasize the importance of educating traditional healers on the fundamentals of mental disorders, including mood and anxiety disorders. Future research should focus on the design and implementation of training programs to increase the mental health literacy and referral practices of traditional healers and to assess the effectiveness of these programs.

\section{Acknowledgements}

We would like to thank the South African Depression \& Anxiety Group (SADAG) who helped in forming a relationship with the traditional healers in the Eastern Cape, and to all the traditional healers who graciously gave up their time to share their practices and experiences with us.

\section{References}

1. Edwards SD. Traditional and Modern Medicine in South Africa A Research Study. Soc Sci Med 1986;22:1273-1276.

2. Freeman M, Motsei M. Planning health care in South Africa: is there a role for traditional healers? Soc Sci Med. 1992;35:1183-1190.

3. Ngubane H. Body and Mind in Zulu medicine. 1977. London: Academic Press.

4. Edwards SD, Grobbelaar PW, Makunga NV et al. Traditional Zulu 
Theories of Illness in Psychiatric Patients. J Soc Psychology 1983;121:213-221.

5. Ensink K, Robertson B. Patient and family experiences of psychiatric services and indigenous healers. Transcul Psychiatr 1999;36:23-43.

6. Freeman $M$, Lee T, Vivian W. Evaluation of mental health services in the Orange Free State. 1994. South Africa: Department of Community Health, University of the Witwatersrand Medical School.

7. Sorsdahl K, Stein D, Grimsrud A et al. Traditional healers in the treatment of common mental disorders in South Africa. J Nerv Ment Dis 2009;1 $197: 434-441$.

8. Stein DJ. Philosophy of psychopharmacology: smart pills, happy pills, and pep pills. 2008.; Cambridge, UK.: New York: Cambridge University Press.

9. Traditional Health Practitioners Act. (Act no. 35 of 2004). Cape Town: Government Printer, Government Gazette. No 29034, [cited 21 July 2006].

10. Department of Health. African traditional medicine for South Africa draft policy. Government Gazette. 7-1-2008.

11. Ashforth A. Witchcraft, Violence and Democracy in South Africa. 2005. Chicago: Chicago University Press.

12. Chew-Graham C, Slade M, Montana $C$ et al. A qualitative study of referral to community mental health teams in the UK: exploring the rhetoric and the reality. BMC Health Serv Res 2007;7:1 17.

13. de Andrade V, Ross E. Beliefs and practices of Black South African traditional healers regarding hearing impairment. Int J Audiol 2005;44:489-499.

14. Okome-Nkoumou M, Kendjo E, Obiang $G$ et al. Delay between first HIV-related symptoms and diagnosis of HIV infection in patients attending the internal medicine department of the Foundation Jeanne Ebori (FJE), Libreville, Gabon. HIV Clinical Trials. 2005;3842.

15. Peltzer K, Mngqundaniso N, Petros G. A controlled study of an HIVIAIDS/STI/TB intervention with traditional healers in KwaZuluNatal, South Africa. Aids and Behavior. 2006;10:683-690.

16. Barker RD, Millard FJC, Malatsi J et al. Traditional healers, treatment delay, performance status and death from TB in rural South Africa. Int J Tuberculosis Lung Dis 2006;10:670-675.

17. Okeke TA, Okafor HU, Uzochukwu BSC. Traditional healers in Nigeria: Perception of cause, treatment and referral practices for severe malaria. J Biosoc Sci 2006;38:491-500.

18. Bartholomew LK, Parcel GS, Kok G. Intervention mapping: A process for developing theory-and evidence-based health education programs. Health Educ Behav 1998;25:545-563.

19. Ajzen I. The Theory of Planned Behavior. Organizational Behavior and Human Decision Processes. 1991;50:179-211.

20. Panday S, Reddy SP, Ruiter RAC et al. Determinants of smoking among adolescents in the Southern Cape-Karoo region, South Africa. Health Prom Int 2007;22:207-217.
21. Aaro LE, Flisher AJ, Kaaya S et al. Promoting sexual and reproductive health in early adolescence in South Africa and Tanzania: Development of a theory- and evidence-based intervention programme. Scand J Pub Health 2006;34:150-158.

22. Sorsdahl KR, Flisher AJ, Stein DJ. Traditional Healer Attitudes and Beliefs Regarding Referral of Mentaly Ill Adult and Adolescent Patients to Allopathic Doctors in the Eastern Cape, South Africa. Transcul Psychiat 2009; 47(4):591-609.

23. Hu L, Bentler PM. Cut off criteria for fit indexes in covariance structure analysis: conventional criteria versus new alternatives. Structure Equation Modeling. 1999;6:1-55.

24. Ngubane H. Body and Mind in Zulu medicine. 1977. London: Academic Press.

25. Bührmann M. Living in Two Worlds. 1984. Cape Town: Human \& Rousseau.

26. Hammondtooke WD. African World-View and Its Relevance for Psychiatry. Psychologia Africana 1975; 1 6:25-32.

27. Schweitzer R. Categories of experience among the Xhosa: A psychological study. Unpublished master's thesis, Rhodes University, Grahamstown, South Africa; 1977.

28. Gumede M. Traditional healers: a medical practitioner's perspective. 1990. Braamfontein: Skotaville Publishers.

29. Bagozzi RP, Baumgartner H, Yi YJ. State Versus Action Orientation and the Theory of Reasoned Action: An Application to Coupon Usage. J Cons Res 1992;18:505-518.

30. Sutton S. The past predicts the future: Interpreting behaviourbehaviour relationships in social psychological models of health behaviour. Social psychology and health: European perspectives. 1994.; Brookfield, VT, US: Avebury/Ashgate Publishing Co.

31. Ajzen I, Fishbein M. Questions raised by a reasoned action approach: Comment on Ogden (2003). Health Psychol 2004;23:431434.

32. Armitage CJ, Conner M. Efficacy of the theory of planned behaviour A meta-analytic review. Br J Soc Pscyhology 2001;40:471-499.

33. Sheppard BH, Hartwick J, Warshaw PR. The Theory of Reasoned Action: A Meta-Analysis of Past Research with Recommendations for Modifications and Future-Research. J Cons Res 1988;15:325-343.

34. Patel V, Musara T, Butau T et al. Concepts of Mental-Illness and Medical Pluralism in Harare. Psychol Med 1995;25:485-493.

35. Aidoo M, Harpham T. The explanatory models of mental health amongst low-income women and health care practitioners in Lusaka, Zambia. Health Policy and Planning. 2001;16:206-213.

36. Sorsdahl K, Stein D, Flisher A. Explanatory models of mental disorders and treatment practices among traditional healers in Mpumalanga. Afr J Psychiatry 2010; 13: 294-290.

37. Freeman M. Providing mental health care for all in SouthAfrica: structure and strategy. 1992. Johannesburg: Centre for Health Policy. 